\title{
A Case of Pulsatile Tinnitus Related to Idiopathic Intracranial Hypertension
}

\author{
Jong-Won Bae ${ }^{\mathbb{D}}$, Kyu-Yup Lee ${ }^{\mathbb{D}}$, Myung Hoon Yoo ${ }^{\mathbb{D}}$, and Da Jung Jung $\mathbb{C}^{\mathbb{D}}$ \\ Department of Otolaryngology-Head and Neck Surgery, School of Medicine, Kyungpook National University, Daegu, Korea
}

\author{
특발성 두개 내 고혈압으로 인한 박동성 이명 1예 \\ 배종원 · 이규엽 · 유명훈 · 정다정 \\ 경북대학교 의과대학 이비인후-두경부외과학교실
}

\author{
Received January 24,2020 \\ Revised April 6, 2020 \\ Accepted April 10, 2020 \\ Address for correspondence \\ Da Jung Jung, MD, PhD \\ Department of Otolaryngology- \\ Head and Neck Surgery, \\ Kyungpook National University, \\ 130 Dongdeok-ro, Jung-gu, \\ Daegu 41944, Korea \\ Tel +82-53-200-5781 \\ Fax +82-53-200-4524 \\ E-mail wjddk0731@naver.com
}

Idiopathic intracranial hypertension (IIH) is a disorder that commonly occurs in obese young women of childbearing age and is characterized by symptoms such as pulsatile tinnitus, dizziness, headache, nausea, vomiting, and visual loss without any structural or vascular abnormalities in the intracranial cavity. We recently experienced a case of a 33 -year-old obese woman who presented with right-sided pulsatile tinnitus, which is an early symptom for IIH. The patient was successfully treated with weight reduction and carbonic anhydrase inhibitor (acetazolamide). Pulsatile tinnitus requires thorough diagnosis and examination because it can be cured if the anatomical or functional cause is identified and treated. When obese women of childbearing age present with pulsatile tinnitus at the otorhinolaryngology outpatient department, treatment for IIH should be initiated after appropriate examination and diagnosis as pulsatile tinnitus may be the only symptom for IIH.

Korean J Otorhinolaryngol-Head Neck Surg 2020;63(9):422-6

Key Words Acetazolamide $\cdot$ Female Idiopathic intracranial hypertension · Obesity · Pulsatile tinnitus.

\section{서 론}

특발성 두개 내 고혈압(idiopathic intracranial hypertension)은 이전 가성뇌종양(pseudotumor cerebri) 또는 양성 두개 내 고혈압(benign intracranial hypertension)으로 불렸 으며 주로 가임기 비만의 여성에게 호발하며 기질적인 병변 없이 뇌압상승으로 인해 박동성의 이명, 어지럼증, 두통, 구 역, 시야장애, 등의 증상과 징후를 포함하는 임상적 기준에 의해 정의된다. 1 차 치료제로 이뇨제가 사용되며 비만의 환자 에게 있어서는 적극적인 체중조절이 함께 병행되어야 한다.

저자들은 특발성 두개 내 고혈압 환자에게 안과적 증상 없 이 초기증상으로 박동성 이명을 주소로 이비인후과 외래를

This is an Open Access article distributed under the terms of the Creative Commons Attribution Non-Commercial License (https://creativecommons.org/licenses/by-nc/4.0) which permits unrestricted non-commercial use, distribution, and reproduction in any medium, provided the original work is properly cited.
내원한 비만의 가임기 33세 여성 환자에게 있어서 체중 조절 과 이뇨제 사용으로 증상이 호전된 특발성 두개 내 고혈압 증례를 경험하였기에 본 질환에 대한 진단 과정 및 치료법, 감별 진단을 위한 검사 정보를 알리고자 본 증례를 보고하 는 바이다.

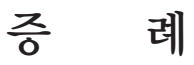

33세 여자 환자가 약 일주일 전부터 우측의 박동성 이명을 주소로 본원 외래를 통해 내원하였다. 환자는 몸무게 $85 \mathrm{~kg}$, 키 $160 \mathrm{~cm}$, 체질량 지수 $33.2 \mathrm{~kg} / \mathrm{m}^{2}$ 으로 비만한 체형이었다. 과거력에서 하시모토 갑상선염 외 특이소견은 없었다. 환자 의 이명 양상은 우측 관자놀이의 맥박과 일치하는 박동성의 이명이 경부의 우측 회전 시 크기가 증가하였으며 반대로 좌 측으로 경부 회전 시 크기가 감소하는 양상을 보이며 우측 
경부 압박 시 이명이 소실되었다. 청력검사 결과 특이소견을 보이지는 않았으며, 혈관성 이명 중에서 정맥성 양상으로 특 발성 두개 내 고혈압, 경정맥구 기형, 경막정맥동의 기형이나 협착 등의 원인 감별을 위한 측두골 컴퓨터단층촬영 및 뇌 자기공명영상 등의 진단적 검사 대기 중 양측 관자놀이의 박 동성 두통 및 양측 시력저하의 발생으로 본원 입원하였다.

입원 당시 시행한 안압은 정상이었으며 안저검사에서 양 측 유두부종과 망막출혈 소견이 있었다(Fig. 1). 요추천자에
서 뇌압은 $400 \mathrm{mmH}_{2} \mathrm{O}\left(50 \sim 200 \mathrm{mmH}_{2} \mathrm{O}\right)$ 로 증가된 소견을 보였고 뇌척수액 생화학 검사는 정상이었다. 뇌압상승소견을 보여 시행한 뇌 자기공명영상(MRI)와 뇌 정맥조영(magnetic resonance venography)에서 뇌실의 확장이나 두개 내 종양 은 없었고 정맥동 혈전도 관찰되지 않았으며 유두부종 시 관 찰되는 양안 시신경을 따라 지주막하의 고강도의 액체저류 와 시신경 유두의 고강도신호가 관찰되었다(Fig. 2).

환자는 요추천자 이후 두통 및 박동성 이명 증상이 일부

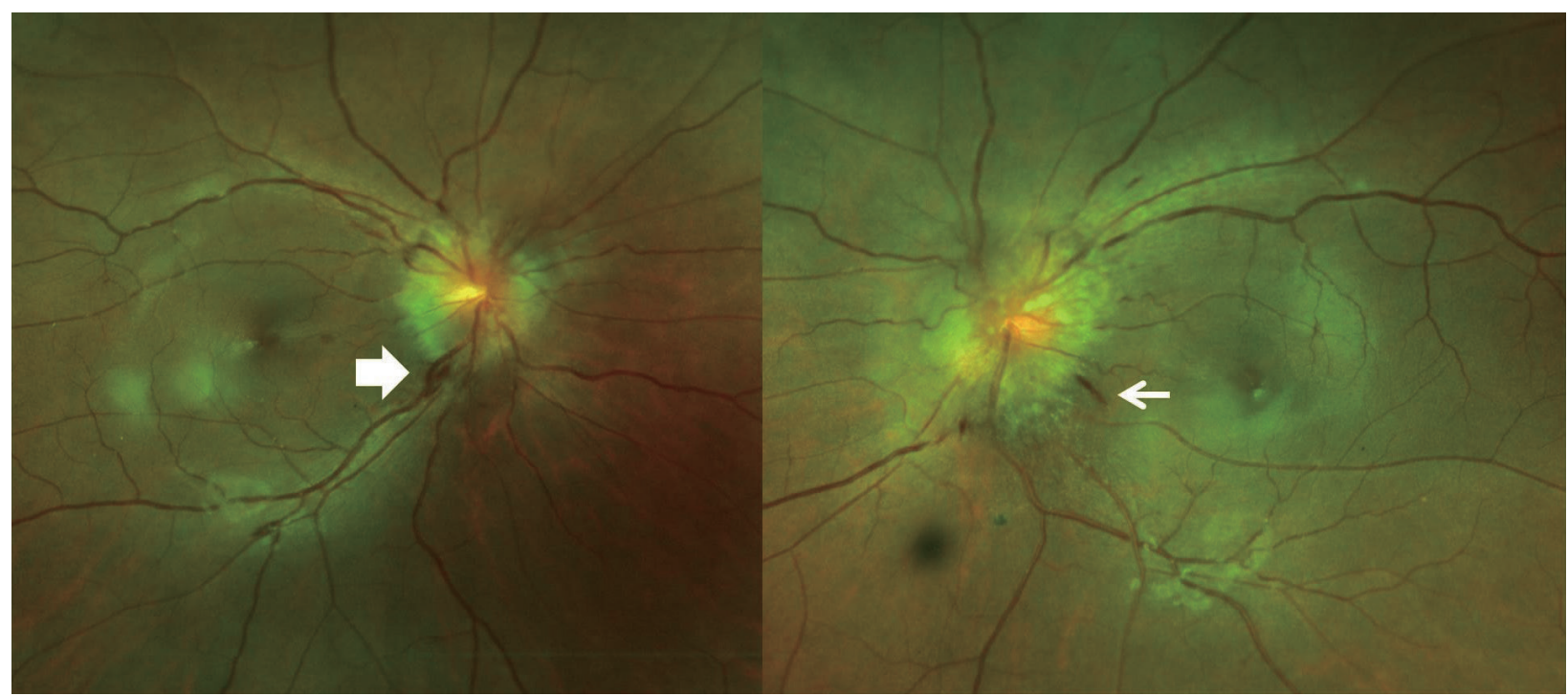

Fig. 1. Right papilledema frisen grade 4 and disc hemorrhage (thick arrow), left papilledema frisen grade 5 and retinal hemorrhage (thin arrow) were observed by opthalmologist.
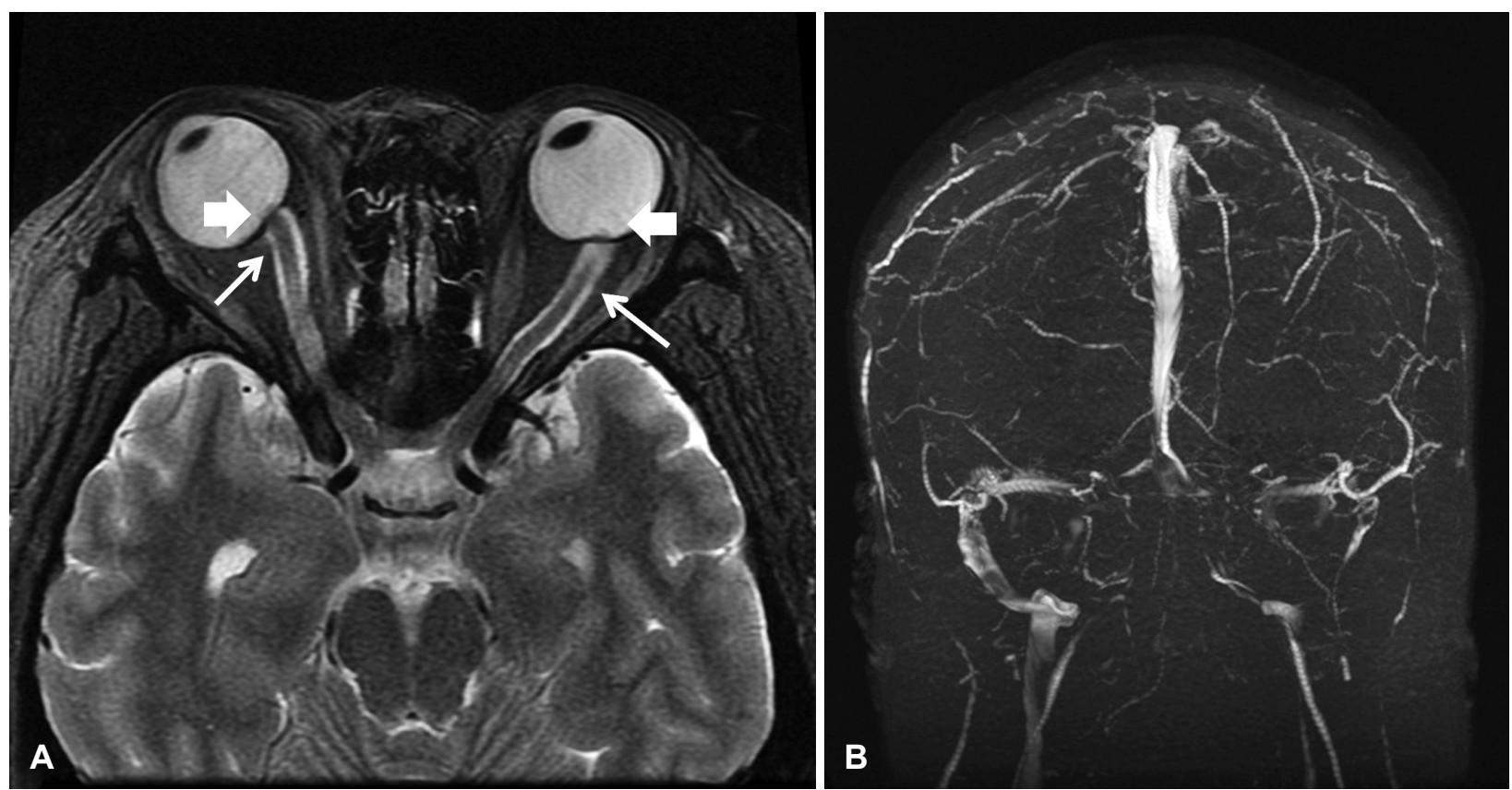

Fig. 2. Neuroimaging features of idiopathic intracranial hypertension. (A) T2-weighted image MRI at the level of the orbit showing hyperintense fluid collection along the bilateral optic nerves (thin arrow) and bulging of bilat-eral optic nerve papillae into the globes (thick arrow). The bulging is more prominent on the left side than the right side. (B) The brain venogram showed no significant venous stenosis and occlusion. 
Table 1. Modified Dandy criteria for idiopathic intracranial hypertension

To make a diagnosis of idiopathic intracranial hypertension, criteria A-E must be satisfied and no known secondary causes should be present. A probable diagnosis of idiopathic intracranial hypertension can be made if only criteria A-D are fulfilled

A) Papilledema

B) Normal neurological examination except cranial nerve abnormalities

C) Neuroimaging: no structural or vascular abnormality on MRI or MR venography; if MRI is unavailable, contrast-enhanced CT can be used

D) Normal CSF constituents

E) Increased CSF opening pressure $\left(>25 \mathrm{cmH}_{2} \mathrm{O}\right)$

호전되었으며 안저검사에서 유두부종 호전양상을 보였다. 환 자의 비만한 체형, 증상과 함께 시행한 뇌 자기공명영상검사 에서 특이소견을 보이지 않고 뇌척수액 생화학 검사 정상소 견이나 뇌압 상승소견이 관찰되어 특발성 두개 내 고혈압으 로 진단하고 아세타졸라마이드 복용과 저염식이, 동시에 체 중감량 치료를 시행하였다. 외래 추적 관찰 중 아세타졸라마 이드 $250 \mathrm{mg}$ bid를 1 개월 가량 복용하였으나 박동성 이명 및 두통 호전되지 않아 아세타졸라마이드 $500 \mathrm{mg}$ bid로 증 량하여 복용 후 2개월 뒤 외래 내원 시 두통과 이명증상이 많이 호전되어 아세타졸라마이드 $500 \mathrm{mg}$ bid를 복용 유지 하며 경과관찰 중이다.

\section{고 찰}

박동성 이명은 단속적이고 맥박과 일치하는 양상의 이명 이며 자세의 변화에 따라 이명의 크기가 변하는 특징을 보인 다. 박동성 이명은 보통 혈액의 와류에 의해 유발되어 대부 분 심박동과 일치한다. 혈관성 이명은 다시 동맥성과 정맥성 으로 분류되며 동맥성 원인은 동정맥 기형, 사구종, 동정맥 루, 두개 내 동맥류, 경동맥의 동맥경화증이 있으며 정맥성은 정맥성 잡음, 특발성 두개 내 고혈압, 경정맥구 기형, 경막정 맥동의 기형이나 협착 등이 있다. ${ }^{1)}$ 박동성 이명의 경우 적절 한 기질적 원인을 확인하여 치료하면 이명의 완치가 가능하 기 때문에 철저한 진단과 검사가 필요하다. ${ }^{2}$ 특히나 두개 내 고혈압 환자의 경우 초기증상으로 박동성 이명, 어지럼증을 주소로 이비인후과를 내원할 수 있다. 동측의 내경정맥을 가 볍게 압박하거나 머리를 동측이나 건측으로 돌리면 정맥성 이명인 경우 변화가 있지만, 동맥성인 경우는 변화가 없다. ${ }^{1)}$ 본 증례에서는 동측의 내경정맥을 압박하거나 머리를 건측 의 방향으로 돌릴 때 박동성의 이명의 크기가 감소하였는데 이는 정맥성 이명을 시사하는 소견이다.

두개 내 고혈압은 뇌의 기질적 병변 혹은 정맥동의 혈전 등에 의해서 유발될 수 있으나 뇌 내부의 구조적 이상이나 종양 등의 특별한 원인 없이 두개 내압이 상승하여 두통, 구
역, 시야장애, 복시, 박동성의 이명, 어지럼증 등의 증상과 징 후를 보이는 경우 특발성 두개 내 고혈압이라 한다. 특발성 두개 내 고혈압 환자에서 가장 흔한 증상은 두통(94\%)이며 다음으로 시야장애(68\%), 박동성 이명(58\%) 증상을 흔하게 호소하였다. 특발성 두개 내 고혈압 환자는 혈관성 이명 양 상으로 정맥성의 특징을 보이며 $62 \%$ 에서 일측 박동성 이명 증상을 호소 하였으며 $2 \%$ 미만에서 양측의 박동성 이명을 호소하였다. ${ }^{3)}$

특발성 두개 내 고혈압은 다른 기질적인 원인을 배제함으 로써 진단 할 수 있으며 변형 Dandy criteria에 따르면 뇌압 상승에 따른 증상과 함께 뇌척수액검사에서 뇌압상승 소견 이외 뇌척수액 조성에 다른 이상소견을 보이지 않으며 영상 학적 검사에서 뇌종양 및 정맥동 혈전의 소견이 보이지 않을 경우 특발성 두개 내 고혈압으로 진단한다(Table 1). ${ }^{4}$ 본 증 례의 경우 변형 Dandy criteria에 따라 Table 1 의 A-E 항목 을 모두 만족하여 특발성 두개 내 고혈압으로 진단 할 수 있 었다.

특발성 두개 내 고혈압 환자의 뇌자기공명영상에서는 두개 내압 상승에 따른 징후들이 나타날 수 있으며 80\%에서 후공 막의 평평(flattening of the posterior sclera), 70\%에서 공허 막(empty sella), 45\%에서 시신경 지주막하의 확장(distension of the perioptic subarachnoid space)의 소견을 보인 다. ${ }^{5)}$ 이러한 영상학적 소견들이 두개 내 고혈압의 진단에 중 요한 도움이 될 수 있다.

특발성 두개 내 고혈압의 정확한 발병기전을 알려져 있지 않으나 대개 가임기의 비만의 여성에게서 흔히 발병하는 것 으로 젊은 여성에게 내분비적 이상과 생리 이상, 경구피임제 복용이 원인적 요소로 제시되나 입증된 바는 없다. 비만은 주요 위험인자로 가장 유력한 가설로 중심성 비만에 의한 복 강 내 압력 증가로 횡격막의 상승을 가져와 흥강 내압이 상 승하여 뇌로부터 정맥 환류의 저항이 높아지게 되어 두개 내 압의 상승을 초래한다고 제시되고 있다.) 비만의 가임기 여 성이 신경학적 증상 없이 박동성 이명을 주소로 이비인후과 외래를 내원하였을 경우 위험인자를 고려하여 특발성 두개 
내 고혈압을 염두에 두어야 한다.

특발성 두개 내 고혈압의 치료 목표는 환자의 증상 호전과 안과적 합병증을 예방하는 것이다. 저염식이 및 철저한 체중 감량과 또는 뇌척수액 생성 감소를 위해 1차 치료제로써 아 세타졸라마이드와 휴로세마이드와 같은 이뇨제를 병행 할 수 있다. 체중감소 및 저염식이를 단독으로 치료한 경우보다 1 차 치료제로 아세타졸라마이드 복용을 함께 한 경우 치료 의 성적이 더욱 좋다는 보고 결과가 있다. ${ }^{7}$ 아세타졸라마이 드와 휴로세마이드를 함께 복용하는 병합요법이 뇌척수액 생성을 억제하여 두개 내압을 낮추는데 효과적일 수 있으나 전해질 불균형 및 산염기 불균형에 의한 대사성 산증의 부 작용 발생 할 수 있어 주의가 필요하다. ${ }^{8,9)}$

만약 약물 치료에 반응을 보이지 않고 두통, 박동성 이명, 시야장애가 심해지거나 약물의 부작용이 나타나 내과적 치 료를 지속할 수 없다면 시신경초 개창술(optic nerve sheath decompression), 요추-복막 션트(lumboperitoneal shunt), 정맥동 스텐트(venous sinus stent), 비만수술(bariatric surgery)와 같은 수술적 치료를 고려하여야 한다.

특발성 두개 내 고혈압은 환자마다 개인차가 심하나 높은 자연관해율을 보이며 4 31\% 환자에서 시력이 저하되고, $5 \%$ 에서는 실명이 초래될 수도 있다. ${ }^{10)}$ Michael 등은 진단 당시 심한 유두부종을 보이는 7명의 환자에서 치료에도 불구하고 시력 저하의 악화 및 실명되었으며 이는 진단 당시의 시력저 하와 시신경부종의 정도가 치료에 있어 중요한 예후 인자임 을 시사한다. ${ }^{11)}$ 추적관찰 기관에 따라 다르지만 $10 ~ 40 \%$ 에서 는 재발함으로 장기적인 추적 관찰이 필요하다. ${ }^{10)}$ 추적 관찰 기간 동안 환자의 체중 변화를 함께 확인하며 특히 재발하 는 환자에게 있어 진단 당시 body mass index와 추적관찰 기간 중 체중 증가가 재발률을 높일 수 있음으로 증상의 관 해 이후 체중조절이 재발에 중요한 인자가 될 수 있다. ${ }^{12)}$ 또 한 시야검사와 유두부종의 정도를 확인하여야 하므로 안과 협진이 이루어지는 것이 바람직하다. 특발성 두개 내 고혈압 은 평생 지속될 수 있는 만성 질환이라 할 수 있기 때문에 완 화된 환자의 경우에도 외래에서 지속적으로 경과 관찰 하여 야 한다.

두개 내 고혈압 환자에게 있어서 안과적 증상 없이 어지럼 증 및 박동성 이명이 초기 증상으로 흔히 나타날 수 있으며 특발성 두개 내 고혈압환자에게 유일한 징후일 수도 있다. 가 임기 비만의 여성이 박동성 이명을 주소로 외래로 내원 하였 을 경우 안과적 및 신경학적 증상이 없더라도 특발성 두개 내 고혈압을 의심할 수 있어야 하며 측두골 컴퓨터단층촬영과 뇌 자기공명영상 촬영을 통하여 기질적 원인의 배제가 필요 하다. 박동성 이명을 유일한 증상으로 환자들은 이비인후과
를 방문하는 경우가 많아 초기에 적절한 검사 및 진단을 통 하여 치료가 시작될 수 있어야 한다. Guo 등 ${ }^{13)}$ 의 연구에 따르 면 박동성 이명을 유일한 증상으로 외래로 내원한 19명의 환 자에게 뇌척수압을 측정하였을 때 13명의 환자에서 뇌척수압 의 상승소견을 보여 특발성 두개 내 고혈압으로 진단되었다.

본 증례는 임상적으로 박동성의 이명 증상을 초기증상으 로 이비인후과 외래로 내원한 환자에게 있어 추후 두통, 시력 저하가 함께 동반되며 안저검사에서 유두부종을 확인하였으 며, 영상검사 결과 두개 내 종괴나 뇌실팽창의 소견을 보이지 않고 뇌척수액검사에서 뇌압상승 소견으로 특발성 두개 내 고혈압으로 진단하였으며 저염식이, 체중조절과 아세타졸라 마이드 복용으로 치료되었던 증례이다. 신경학적 증상 없이 박동성 이명을 주소로 이비인후과 외래를 내원하는 가임기 의 비만 여성의 경우 초기에 특발성 두개 내 고혈압의 가능 성을 고려하여 적절한 진단을 통한 증상 조절과 안과적 합병 증을 예방하는 것이 중요할 것이다.

\section{Acknowledgments}

None.

\section{Author Contribution}

Conceptualization: Da Jung Jung. Data curation: Jong-Won Bae. Formal analysis: Myung Hoon Yoo. Funding acquisition: Da Jung Jung. Investigation: Da Jung Jung. Methodology: Jong-Won Bae. Project administration: Kyu-Yup Lee. Resources: Myung Hoon Yoo, Kyu-Yup Lee. Software: Da Jung Jung. Supervision: Da Jung Jung. Validation: Myung Hoon Yoo, Kyu-Yup Lee. Visualization: Da Jung Jung. Writing—original draft: Jong-Won Bae. Writing—review \& editing: Da Jung Jung.

\section{ORCIDs}

Da Jung Jung Jong-Won Bae Kyu-Yup Lee Myung Hoon Yoo https://orcid.org/0000-0001-6178-6113 https://orcid.org/0000-0002-0874-0623 https://orcid.org/0000-0001-7170-4847 https://orcid.org/0000-0002-9158-8924

\section{REFERENCES}

1) Son WR, Park SY, Hwang SH, Lee HS. A case of pulsatile tinnitus by sigmoid sinus diverticulum. Korean J Otorhinolaryngol-Head Neck Surg 2008;51(8):734-7.

2) Sonmez G, Basekim CC, Ozturk E, Gungor A, Kizilkaya E. Imaging of pulsatile tinnitus: A review of 74 patients. Clin Imaging 2007;31(2):102-8.

3) Giuseffi V, Wall M, Siegel PZ, Rojas PB. Symptoms and disease associations in idiopathic intracranial hypertension (pseudotumor cerebri): A case-control study. Neurology 1991;41(2):239-44.

4) Markey KA, Mollan SP, Jensen RH, Sinclair AJ. Understanding idiopathic intracranial hypertension: Mechanisms, management, and future directions. Lancet Neurol 2016;15(1):78-91.

5) Brodsky MC, Vaphiades M. Magnetic resonance imaging in pseudotumor cerebri. Ophthalmology 1998;105(9):1686-93.

6) Sugerman HJ, DeMaria EJ, Felton WL 3rd, Nakatsuka M, Sismanis A. Increased intra-abdominal pressure and cardiac filling pressures in obesity-associated pseudotumor cerebri. Neurology 
1997;49(2):507-11.

7) Biousse V, Bruce BB, Newman NJ. Update on the pathophysiology and management of idiopathic intracranial hypertension. J Neurol Neurosurg Psychiatry 2012;83(5):488-94.

8) Schoeman JF. Childhood pseudotumor cerebri: Clinical and intracranial pressure response to acetazolamide and furosemide treatment in a case series. J Child Neurol 1994;9(2):130-4.

9) Lee AG, Anderson R, Kardon RH, Wall M. Presumed "sulfa allergy" in patients with intracranial hypertension treated with acetazolamide or furosemide: Cross-reactivity, myth or reality? Am J Ophthalmol 2004;138(1):114-8.

10) Shah VA, Kardon RH, Lee AG, Corbett JJ, Wall M. Long-term follow-up of idiopathic intracranial hypertension: The Iowa experience. Neurology 2008;70(8):634-40.

11) NORDIC Idiopathic Intracranial Hypertension Study Group Writing Committee, Wall M, McDermott MP, Kieburtz KD, Corbett JJ, Feldon SE, et al. Effect of acetazolamide on visual function in patients with idiopathic intracranial hypertension and mild visual loss: The idiopathic intracranial hypertension treatment trial. JAMA 2014;311(16):1641-51.

12) Ko MW, Chang SC, Ridha MA, Ney JJ, Ali TF, Friedman DI, et al. Weight gain and recurrence in idiopathic intracranial hypertension: A case-control study. Neurology 2011;76(18):1564-7.

13) Guo P, Sun W, Shi S, Wang W. Patients with pulse-synchronous tinnitus should be suspected to have elevated cerebrospinal fluid pressure. J Int Med Res 2019;47(9):4104-13. 